\title{
EL TERRITORIO ALICANTINO EN LAS FUENTES GEOGRÁFICAS ÁRABES MEDIEVALES (SIGLOS IX-XV)
}

\author{
Antonio José Sánchez Pérez* \\ Rosario del Carmen Alonso de la Cruz**
}

\section{RESUMEN}

Este artículo es una recopilación de las fuentes geográficas árabes medievales que aluden al actual territorio de la provincia de Alicante, que perteneció a la Cora de Tudmir. Las fuentes recogidas (siglos IX al XV) abarcan un período aproximado de seiscientos años. Debido a la amplia cronología y a la dispersión de los textos constituyen unas fuentes de difícil acceso. Asimismo, recogemos unas pequeñas biografías de los autores más significativos. Esta recopilación puede ser de utilidad en el estudio y futura localización de ciudades islámicas aún sin identificar.

Palabras clave: Alicante, Islam, geografía, Tudmir.

\section{RESUMÉ}

Cet article est une compilation des sources géographiques arabes médiévales qui parlent sur le territoire actuel de la province d'Alicante, qui a appartenu à la Cora de Tudmir. Les sources recuillies (IX au XVe siècle), comprendent presque six cents années. 'A cause de l'ample chronologie et de la dispersion des textes, elles constituent des sources très difficiles à accéder. Aussi, nous reprenons de petites biographies des auteurs les plus significatifs. Ce recueil peut être utile pour l'étude et la prochaine localisation de villes islamiques encore inconnues.

Mots-clé: Alicante, Islam, géographie, Tudmir. 


\section{INTRODUCCIÓN}

La historia y la geografía ocuparon un lugar importante en la sociedad árabe musulmana. A menudo, las obras de historia contenían gran cantidad de información geográfica acerca de los países, sus gentes, recursos, topografía, ríos, montañas y carreteras.

En la época preislámica, las especulaciones cosmológicas y geográficas se limitaban a algunas nociones tradicionales, a topónimos de Arabia y de los países vecinos. Desde principios del califato Abbasí y tras la transferencia de la capital del Imperio a Bagdad, los árabes enriquecieron sus conceptos primitivos con datos nuevos sacados de la ciencia geográfica india, irania y griega, cuyas obras se estudiaron. Esta literatura geográfica que se desarrolló en Oriente desde el siglo IX al XI, serviría de modelo a los letrados de al-Andalus. En sus obras se estudiaba el mundo en general y de forma más detallada el Imperio Abbasí. En ellas aparecen descritos el sistema de comunicaciones y la topografía de este imperio.

A pesar de su aislamiento político del Este a partir de 711, y de su independencia en 756, al-Andalus continuó atrayendo la atención de historiadores, biógrafos y geógrafos orientales. Pero sobre todo, el historiador andaluz en general, escribió muy detalladamente, y sus relatos incluyen a menudo largos poemas y valiosos datos geográficos sobre ríos, canales, puentes, topografía de ciudades, mezquitas, palacios y otros monumentos.

La geografía y la historia eran interdependientes en muchos aspectos; y aunque «Geografía» es un término griego, hizo grandes avances con los geógrafos musulmanes. Los estudios geográficos tuvieron su comienzo en el Este, y fueron seguidos de modo teórico y práctico en todo el ámbito musulmán. Este campo surgió, sin duda, de las necesidades religiosas, militares y administrativas, así como de la curiosidad por conocer la Tierra, su forma, posiciones, longitud y latitud.

La geografía descriptiva fue inmediatamente aplicada a empresas religiosas, militares y administrativas, y fue escrita por eruditos errantes que reunieron la información necesaria para provecho de gobernantes, funcionarios y el público en general. Como los musulmanes debían de ponerse de cara a La Meca durante sus rezos, era imprescindible fijar su posición respecto a la Ciudad Sagrada, y al mandar el Islam que los fieles deben hacer una peregrinación a La Meca y Medina una vez durante su vida, la necesidad de saber geografía cobró importancia, acrecentándose enormemente al extenderse el imperio islámico por varios territorios. De este modo, muchas obras de geografía fueron escritas con un fin práctico, y otras como entretenimiento. Algunas de las primeras trataron de temas específicos como la topografía, el clima y los recursos naturales. Otras trataron de las características de los países, y al principio, todas ellas tuvieron un campo limitado, pero fueron seguidas por otras más amplias en forma de compendios, diccionarios geográficos $\mathrm{y}$ relatos de viajes.

Los geógrafos musulmanes reunieron su información a través de datos escritos, informadores, o sus propios viajes; y algunos de ellos escribieron sobre geografía por propia iniciativa, aunque otros lo hicieron por orden de los gobernantes. Su interés no se limitó a los países musulmanes, sino que se hizo extensivo a China, Rusia, India, los Balcanes y otros países, y el contenido de las obras dependió de la inclinación de cada autor, pudiendo incluir historias, anécdotas, leyendas, información histórica sobre los pueblos, sus costumbres y 
religión, rutas de los mercaderes, productos agrícolas y vestidos, cosmografía, descripciones de ciudades, ríos, montañas, monumentos, cosas extrañas y maravillosas ...

A continuación recogeremos algunos ejemplos de estos textos; los que hacen referencia al territorio de la actual provincia de Alicante.

\section{AL-YAQŪBI (s. IX)}

Geógrafo oriental del siglo IX. Escribió su obra «Kitāb al-buldān» en torno al año 890. Su muerte se fecha en el año 897. El «Kitāb al-buldān» es la primera obra geográfica árabe que hace referencia al territorio de nuestra área de estudio.

Texto:

«Salga de Qairawan hacia Túnez. Allí se embarca y viaja por mar diez días, siguiendo la costa y sin penetrar tierra adentro, hasta que se encuentra enfrente de la península de al-Andalus, en un lugar llamado Tenes, que está en la costa a cuatro jornadas de la ciudad de Tahert. Se dirige entonces a la península de al-Andalus cortando la alta mar durante un día y una noche, hasta que llega al país de Tudmir, región amplia y habitada, en la que hay dos ciudades llamadas respectivamente ALASKAR y Lorca, ambas con mezquita mayor. Después se sale hacia ... Córdoba ... (por) ... Elbira ...»

En este texto queremos destacar la mención que al-Yaqūbi hace de la ciudad de al-Askar («el campamento militar»). La ubicación exacta de esta ciudad no se ha podido determinar hasta ahora. Codera y Asín Palacios (ASIN PALACIOS, 1944) identificaron al-Askar con el despoblado de Alasquer, próximo a la ciudad de Alcira. Sin embargo Pierre Guichard (GUICHARD, 1985) localiza esta ciudad fortificada o castillo (hisn) en las zonas fronterizas entre la Cora de Tudmir y la de Valencia, probablemente en las comarcas montañosas del norte de la provincia de Alicante. Para ello se basa en un documento cristiano del siglo XIII que sitúa en esta zona una sierra de Alascar, que probablemente conservaría el nombre de la ciudad o fortaleza desaparecida. En agosto de 1276 el rey de Aragón concertó una tregua con la mayor parte de los musulmanes de esta región que se habían sublevado; exceptuándose sin embargo, un grupo de castillos que no se habían rendido e incluían los actuales lugares de Vall de Laguart, Altea, Pedreguer, Vall de Pop, Relleu, y las sierras de Confrides y Alascar. Por tanto, para Guichard, sería al-Askar un distrito septentrional de la Cora de Tudmir y situado entre Denia, Alicante y Alcoy. Según este mismo autor la ciudad de al-Askar sería destruida hacia el año 929 por rebelarse contra el poder Omeya.

\section{AL-RĀZī (s. X)}

En el siglo X Ahmad al Rāzī fue el artífice de la eclosión de la geografía andaluza. Su descripción de España contiene una parte geográfica. Casi todos los geógrafos hispanoárabes siguen en su descripción el esquema trazado por este cronista cordobés, nacido en el año 889 y fallecido en 935. Su obra, titulada Ajbār mulūk al-Andalus, nos ha llegado como la «Crónica del moro Rasis», una traducción mandada hacer por el rey Don Dionís 
de Portugal hacia el año 1300. El arabista galo Levi Provençal hizo una reconstrucción del texto original que es la que reproducimos a continuación.

Texto:

«El distrito de Jaén es contiguo al de Tudmir, el cual se encuentra al Este de Jaén y al Oeste de Córdoba. Es una región muy apreciada, de muy buenos árboles, y todo su territorio está irrigado por el río, de la misma manera que el Nilo en Egipto. Su suelo tiene propiedades naturales favorables, y allí se encuentran numerosas minas de donde se extrae plata en cantidad.

Tudmir reúne a la vez las bondades marítimas y terrestres; posee buenos campos, buenas ciudades y castillos bien defendidos, como la ciudad de Lorca, la de Murcia y la de Orihuela, que es una ciudad de la antigüedad, donde los antiguos vivieron por largo tiempo.

Otra localidad es Alicante. Se encuentra en la Sierra de Benicadell (Banu 1-Qatil), a partir de la cual nacen otras montañas donde se encuentran varias buenas ciudades, en las cuales se fabrican muy buenas telas de seda. Sus habitantes eran malas gentes y de malas maneras, pero muy hábiles en sus obras.

Una de sus ciudades es Cartagena, que fue llamada por los musulmanes al-Qayrawan (Alquirone). Hay también un puerto que se llama Denia, muy bueno y muy antiguo.»

El interés de este texto de al-Rāzī radica en que estamos ante la primera obra geográfica árabe que menciona ciudades de la actual provincia de Alicante, como Orihuela, Denia y la propia Alicante. También menciona la Sierra de Benicadell, situada al norte de la provincia.

\section{AL-UDR̄̄ (s. XI)}

Nació en Dalāya, la actual Dalías (Almería) en el año 1002-1003. Su nombre completo es Ahmad ibn Umar al-Udrī.

Una de las pocas cosas que sabemos de su vida es que realizó con sus padres un largo viaje por Oriente, donde siguió las enseñanzas de reputados maestros. De vuelta a al-Andalus, contó con numerosos discípulos, entre ellos, al-Bakrī e Ibn Hazm. Al-Udrī murió en 1085.

La obra de al-Udrī, que nos ha llegado incompleta, el Tarsī al-Ajbār, pertenece al campo de la historia y de la geografía, aunque esencialmente es una obra geográfica. Su obra tiene gran importancia desde el punto de vista historiográfico, porque es el eslabón más antiguo conocido en la cadena de transmisión que parte de al-Rāzī (s. X) y llega hasta el siglo XIV con la gran obra de al-Himyarī.

Texto:

Descripción hidro-geográfica de la Cora de Tudmir.

«...el río de Tudmir posee norias que riegan las huertas de este territorio. El comienzo de la acequia que parte del río están en Qantara Askaba (Alcantarilla), y alcanza las pro- 
piedades de los habitantes de la ciudad de Mursiya (Murcia), hasta el límite territorial de la alquería de Taws (¿Cox?), que es una de las alquerías de la ciudad de Orihuela (Uryula). Los habitantes de la ciudad de Orihuela abren una acequia en este río, acequia que arranca de sus tierras (¿Acequia Mayor de Callosa?) hasta llegar al paraje denominado al-Qatrullat. La longitud y extensión de esta acequia es de 28 millas. Su cauce concluye al sur de este paraje, en la nahiya (región agrícola) llamada de al-Muwalladin en dirección a la alquería conocida por al-Yuzahira. De allí el río se dirige hacia el mar, siendo conocido aquel lugar por el nombre de al-Mudawwir».

Consideramos que este texto es de gran interés ya que es la primera fuente árabe que describe la Vega Baja del Segura. Menciona la ciudad de Orihuela y una de sus alquerías, llamada Taws, de localización desconocida pero que podría referirse a Cox. Después se menciona el paraje de al-Qatrullat, que ya Molina López identifica con Catral (MOLINA LÓPEZ, 1972). Después se menciona la nahiya de al-Muwadallin, que para Molina López tiene el significado de «los conversos» o «muladíes». Por tanto es posible que el paraje de al-Muwadallin albergara población indígena convertida al islam (MOLINA LÓPEZ, 1972); este paraje se identifica espacialmente con las tierras que conforman la actual Almoradí (AZUAR RUIZ Y GUTIÉRREZ LLORET, 1985). Este paraje de al-Muwadallin se menciona también en el «Libro del Repartimiento de Orihuela» (TORRES FONTES, 1988), aunque no ha podido ser documentado arqueológicamente.

También menciona el texto de al-Udrī la alquería de al-Yuzahira. Rafael Azuar y Sonia Gutiérrez proponen leer al-Yâzira y creen que puede corresponderse con la alquería de Algezira (AZUAR RUIZ Y GUTIÉRREZ LLORET, 1985), mencionada en el «Repartimiento de Orihuela» en la segunda y en la tercera partición, y que podría situarse en las proximidades de Algorfa.

El último topónimo de este texto, al-Mudawwir, ha sido y sigue siendo objeto de discusión. Ya a finales del siglo XVIII Don Juan Lozano en su obra «Bastetania y Contestania del Reino de Murcia» localizaba Almodóvar en la Vega Baja del Segura, concretamente entre Orihuela y Almoradí. Desde entonces han sido muchos los investigadores que se han ocupado de la localización de al-Mudawwir-Almodóvar. El término Almodóvar es un topónimo de indiscutible etimología árabe y viene a significar «el redondo», «dar vueltas» y «rodear», ajustándose a las condiciones del terreno de algunas poblaciones homónimas como Almodóvar del Río (Córdoba), Almodóvar del Campo (Ciudad Real), Almodóver (Huesca) muy próximas a ríos. Por tanto Almodóvar significaría «el rodeado», aludiendo a la ubicación en un meandro del río.

El traductor castellano de al-Udrī (MOLINA LÓPEZ, 1972) cree que Almodóvar no se trata de una localidad, sino más bien de un apelativo geográfico- descriptivo referido a la desembocadura del Segura. Posteriormente autores como Mikel de Epalza (EPALZA, 1980), Carmen Barceló (BARCELÓ, 1985) y Rafael Azuar (AZUAR, 1989) identificaron el topónimo Almodóvar con la actual Guardamar del Segura o con la Rábita califal de las Dunas de Guardamar. Pero más recientemente, las investigaciones de Antonio García Menárguez (GARCÍA MENÁRGUEZ, 1989) llevan a localizar Almodóvar entre las localidades de Rojales y Guardamar, y más concretamente en el Cabezo Soler (Rojales) donde ya existía un asentamiento anterior con fuerte sustrato desde época tardorromana o precalifal. Cuando en el siglo XIII (rebelión mudéjar de 1266) desaparezca la Almodóvar 
islámica se creará de nueva planta la ciudad cristiana de Guardamar, aunque durante algún tiempo se mantenga en las fuentes históricas y documentos de la época la confusión entre Almodóvar y Guardamar.

El topónimo Almodóvar referido a la desembocadura del Segura aparecerá en otros autores árabes como al-Idrisi y ad-Dimasqhi, como veremos posteriormente.

\section{La Peña del Lobo en la Cora de Tudmir}

«Me contaron que en la costa de Elche, perteneciente a la Cora de Tudmir, en el puerto llamado de Santa Bula, había una peña conocida por la «Peña del Lobo». Si un lobo o un león se acercaba a ella, no atacaba, pues toda su ferocidad natural desaparecía mientras permanecía sobre aquella peña»

Esta noticia o hecho fantástico que relata al-Udrī será reproducida por al-Himyarī en el siglo XIV. ¿Sería el antecedente del Paso del Lobo mencionado por Madoz en el siglo XIX y del paraje que aún conserva ese nombre, en Santa Pola? Según Mikel de Epalza el actual puerto de Santa Pola se llamaría en época islámica Shant Paul (San Pablo) y no Santa Paula, porque la terminación femenina se la dieron los árabes, como a todos los nombres de ciudades e islas.

\section{Referencias a terremotos en la Cora de Tudmir.}

«Dijo Ahmad b. Umar con relación a unos terremotos ocurridos en la nahiya de la ciudad de Murcia y en la de Orihuela. Se produjeron unos terremotos en el territorio de Tudmir, en las ciudades de Orihuela y Murcia y en el espacio comprendido entre ambas. Aquello se produjo después del año 404 de la Hégira (13 de Julio de 1013 a 2 de Julio de 1014) y duró aproximadamente un año. Todos los días se presentaban varias veces; no pasó ni un solo día ni una noche en que no aparecieran estos terremotos. Las casas se derrumbaron, las torres se abatieron, así como todos los edificios altos. La mezquita mayor de Orihuela se derrumbó junto a su minarete; la tierra se abrió por toda la región. Muchos manantiales desaparecieron bajo tierra y surgieron otros que manaban un agua hedionda».

Los efectos catastróficos de estos terremotos del siglo XI nos recuerdan mucho a los de los terremotos alicantinos de 1829. También queremos destacar que ésta es la primera mención histórica de movimientos sísmicos en la zona.

\section{Breve descripción de la ciudad de Denia.}

«Daniya es un conocido puerto del amal de Tudmir. Es una ciudad antigua y primitiva que se menciona en la división administrativa de Constantino, que se hiciera de al-Andalus».

\section{Breve descripción de la ciudad de Orihuela}

«El significado de Orihuela en latín es «la aurífera». Es una ciudad antigua, capital de ayam (extranjeros, cristianos) y sede de su gobierno». 


\section{Itinerarios.}

«Desde la ciudad de Orihuela a Elche hay 15 millas; de Elche al castillo de Alicante, 6 millas».

\section{Distritos y partidos agrícolas alicantinos.}

«...el distrito de al-Askar, el distrito de Ils (Elche)...» «...ŷuz (partido agrícola) al Bayda'wa-l-Galinar (partido de Albaida y Gallinera), ŷu Bani Gatil (partido de Benicadell) ŷuz Qusantaniya (de Cocentaina)».

En la parte histórica referida a Tudmir, al- 'Udrī menciona unas alquerías situadas en nuestra zona de estudio. Recogemos a continuación el texto:

«Abd al-Yabbar b. Nadir se había establecido con las tropas sirias de Baly en el barrio occidental de Córdoba (mediados del siglo VIII), dando nombre a una de sus puertas: Bad Abd al-Yabbar. Más tarde se trasladó al Levante y entabló relaciones con Teodomiro, cristiano no árabe, señor de Orihuela, quien entregó como dote por el casamiento de su hija la alquería de Tarsa, próxima a Elche, situada a unas tres millas de distancia, y la alquería conocida por Tall al-Jattab, situada a unas ocho millas de Orihuela.»

La alquería de Tall al-Jattab ha sido identificada (GUTIÉRREZ LLORET,1995) con el asentamiento emiral del Cabezo de las Fuentes (Albatera), un despoblado situado a doce kilómetros de Orihuela. En cuanto a la alquería de Tarsa, hoy por hoy, es imposible su localización.

\section{AL-BAKRI (s. XI)}

Abu 'Ubayd al-Bakri nació en 1014 en Saltes de una familia noble. En el año 1001, su abuelo se había hecho con el gobierno de Huelva y Saltes y se independizó del gobierno central cordobés en 1011. En 1051 al-Bakri se vio forzado a emigrar a Córdoba cuando los abbadíes de Sevilla se apoderaron de este pequeño estado. Después de 1064 se trasladó a Almería donde formó parte de los círculos cortesanos y allí terminó sus estudios. En 1085 fue enviado a la corte abbadí de Sevilla en misión diplomática, y decidió establecerse allí, donde murió en 1094.

Al-Bakri fue un erudito prolífico, hombre de letras, filólogo, poeta, botánico e historiador, y está considerado como el principal geógrafo de al-Andalus. Su obra principal titulada «Masālik wal-mamālik» se ocupa de todo el mundo conocido en su época, pero no se conserva en su totalidad. Los fragmentos que han llegado hasta nosotros se refieren a Siria, Iraq, al-Andalus, y, sobre todo, Sudán y África del Norte. Precisamente los fragmentos que recogemos a continuación pertenecen a la descripción de al-Bakri de África del Norte, pues en la descripción de al-Andalus no se menciona el territorio alicantino.

\section{Texto:}

«... El puerto de Tenes tiene en frente, en tierras de al-Andalus, Santa Pola (Sant Būl). 
Sigue al puerto de Tenes, hacia el este, a más de veinte millas, el puerto de la isla de Wuqūr. Tiene un pequeño río que vierte sus aguas en el mar. La isla está cerca de tierra firme. Tiene enfrente, en tierras de al-Andalus, el puerto de Alicante (Laqant). Se corta el mar, entre los dos, en cinco etapas.

Después está el puerto de Cherchel, que tenía una ciudad que fue importante antiguamente y que no está habitada. Se puede sacar agua del suelo. Está protegida por el este y el oeste. La ciudad de Cherchel tenía un puerto construido, que ahora está rellenado. Hay fortalezas religiosas en las que se reúne cada año mucha gente. Tiene enfrente, a cinco jornadas y media el puerto de Mudaira (Moraira).

Le sigue el monte de Senwa. Tiene un puerto llamado al-Batāl. No está habitado. Está protegido de los vientos del oeste. Tiene agua que corre. Tiene enfrente, a cinco jornadas, en la orilla opuesta de al-Andalus, el monte Qarūm (el Montgó, en Denia).

Le sigue el puerto de Yanabiya. Tiene una isla. Aquí había antiguamente una ciudad. No está habitada. Tiene un río que se echa al mar. Tiene enfrente, en las tierras de al-Andalus, a seis jornadas, el puerto de Denia (Dāniya).»

En este texto se mencionan los principales puertos de la zona en el siglo XI: Santa Pola, Alicante, Moraira y Denia.

\section{AL-RUSATĪ (ss. XI-XII)}

El genealogista oriolano Abū Muhammad al-Rusatī escribió una obra titulada «Iqtibās al-anwār wa iltimās al-azhār fi ansāb al-sahāba wa rubāt al-atār». Esta obra, aún siendo básicamente una obra genealógica, contiene datos de interés geográfico-histórico de alAndalus.

Texto:

\section{ORIHUELA}

«Al-Ūriyūli: Orihuela es una da las siete ciudades del pacto de Teodomiro y una de las fortalezas de al-Andalus. En ella hay abundancia de bienes y se dan magníficas cosechas. Nací y me crié en esta ciudad y en ella también están enterrados mis padres y mis abuelos -Dios se apiade de ellos-.

Entre los sabios que portan su nisba (especie de gentilicio) figura el alfaquí y cadí Abū-l-Qāsim Jalaf b. Sulaymān b. Muhammad b. Fathūm. Fue nombrado cadí en Játiva y Denia, pero renunció al cargo. Después volvió a su tierra, pero no salía de su casa más que para hacer la oración del viernes o para algo similar. Piadoso, asceta, asiduo practicante del ayuno, de recto proceder, afable, generoso con sus compañeros, de buen trato y excelentes relaciones con hermanos y familiares. Experto en materia judicial y una autoridad en materia notarial. Compuso una obra, «Al-Tambīd», además de ser un buen poeta. Murió en Orihuela, un miércoles día 2 del mes de Dū-1-qa'da del año 505 (1 de mayo de 1112).

Su hijo, el hafiz Abū Bakr Muhammad aprendió, además de su padre, del hafiz Abū Alī al-Sadafī casi la mitad de la obra de Abū Umar ibn Abd al-Barr. Compuso también una obra comentario sobre los errores que aquella contenía. Murió en su tierra la noche del martes, a comienzos del mes de Dū-l-hiŷŷa del año 517 (20 de enero de 1124). Oró 
sobre su tumba el qādī-l-qudā del Levante Abū Muhammad ibn Abī Aryūn que se había desplazado desde Murcia expresamente para ello.»

Este texto tiene el interés de haber sido escrito por un autor de la tierra, el oriolano al-Rusatī y de darnos a conocer a oriolanos ilustres del siglo XII, prácticamente desconocidos hasta ahora.

\section{AL-IDRĪS̄̄ (s. XII)}

Muhammad al-Hammūdī, famoso con el nombre étnico de al-Idrīsī, nació en Ceuta (1099/1100) e hizo sus estudios en Córdoba. Siendo aún joven realizó largos viajes por Asia Menor, norte de África y España y dio la vuelta a Francia. Con anterioridad al año 1154, fue llamado a Sicilia por el rey normando Roger II, que había convertido su corte de Palermo en un brillante centro de estudios. A petición de este soberano, al-Idrīsī hizo preparar un planisferio de plata que contenía las siete zonas del mundo, con la posición de los continentes, los mares, los ríos, los desiertos, las ciudades y las vías de comunicación. En base a sus observaciones personales, y a las sacadas de otros viajeros acometió la redacción de una amplia obra de geografía que concluyó hacia 1154, la «Nuzhat al-musthtāq fi ijtirāq al-āfāq» («Diversión para aquel que desee recorrer el mundo»), llamada a veces «El libro de Roger». La parte referente a España fue redactada entre los años 1147 y 1148. Al-Idrīsī también redactó una obra menor titulada «Uns al-Muhay», un itinerario donde se recogen los caminos y distancias entre ciudades españolas. Al-Idrīsī murió en 1165.

\section{Texto:}

«...Denia es una bonita villa marítima, con un arrabal bien poblado. Está ceñida por fuertes murallas y estas murallas del lado de oriente han sido prolongadas hasta el mar, con mucho arte e inteligencia. La villa está protegida por un castillo fuerte. Está la villa rodeada de campos cultivados de viñedos y plantaciones de higueras. Muchos barcos acuden allí y hay también arsenales donde se construyen. De allí parten navíos que van a las regiones más lejanas, y de allí sale también la escuadra en tiempo de guerra.

Al mediodía de esta villa hay una montaña redonda, desde cuya cima se ven los montes de Ibiza sobre el mar. Esta montaña se llama Qawun (Mongó).

Elche es una villa construida en una llanura y atravesada por un canal derivado del río. Este canal pasa bajo sus muros, los habitantes hacen uso de él, porque sirve para los barcos y corre por los mercados y las calles. Las aguas del río que citamos son saladas. Para beber los habitantes, tienen necesidad de traer de otros puntos agua de lluvia, que conservan en aljibes.

De Elche a Orihuela, villa construida sobre el río Blanco (Nahr al-Abyad, Segura), que es también el río de Murcia, 28 millas.

Los muros de Orihuela del lado del Oeste, son bañados por este río; un puente de barcas da acceso a la villa. Está defendida por un castillo muy fuerte, construido sobre la cumbre de una montaña y está rodeada de jardines y huertos, juntos unos a otros, que producen frutos en cantidad prodigiosa. Allí se gozan todas las comodidades de la vida. Hay bazares y alquerías. 
Desde Orihuela al mar, 20 millas.

De Orihuela a Murcia, 12 millas.

Y a Cartagena, 45 millas.

De Denia, villa marítima, de la que se ha hecho mención, a Alicante, dirigiéndose al oeste y siguiendo la costa, 70 millas.

Alicante es una ciudad, pequeña, de buenas construcciones. Tiene zoco, mezquitaaljama y otra mezquita con predicación. Exporta esparto a todos los países del mar. Hay muchas frutas y legumbres, higos y uvas. Tiene una alcazaba, muy inasequible y elevada, en lo más alto de un monte, al que se sube con fatiga y cansancio. En ella, a pesar de su pequeñez, se construyen naves para largos viajes y barcazas. Cerca de esta ciudad, hacia el oeste, hay una isla llamada Planesa (Tabarca). Está a una milla de la costa. Es un buen fondeadero, que puede servir a las naves del enemigo. Está frente al Promontorio del Observatorio. Desde el Promontorio del Observatorio a la ciudad de Alicante hay 10 millas. Desde la ciudad de Alicante, por tierra, a la ciudad de Elche hay una jornada escasa. Desde la ciudad de Alicante a las gargantas de Palos hay 57 millas.»

A continuación recogemos los fragmentos del «Uns al-Muhay» referidos a los caminos y distancias entre ciudades alicantinas islámicas.

Texto:

\section{Las distancias de Tudmir.}

«...De Murcia a Orihuela hay doce millas; de Orihuela a Elche (Ils) hay dieciocho millas...»

«...De Murcia al castillo de Crevillente hay una etapa; entre Crevillente

y Orihuela hay veinticinco millas...»

«De Orihuela a Alicante hay treinta millas;

de Alicante a Elche hay doce millas...»

\section{La ruta de Murcia a Valencia:}

«De Murcia a Orihuela hay doce millas, de Orihuela a Albatera (Al-Butayra), donde está el parador, hay seis millas, de Albatera al castillo de Aspe (Asf) hay seis millas, al castillo de la Mola (Mūla, al sur de Monóvar) que está a las orillas del río Vinalopó (Río de Elche) hay seis millas, al castillo de Petrel (Batrir) hay una etapa cuyas millas son treinta y cinco, de Petrel al castillo de Biar (Biyar)...»

\section{La ruta de Játiva a Denia:}

«De Játiva al castillo de Bairén (Bayran) hay dieciocho millas, de Bairén al castillo de Orba (Urba) hay doce millas, de Orba a Denia hay doce millas.» 


\section{Los embarcaderos de Barcelona a la ciudad de Algeciras:}

«...A Denia (desde el castillo de Cullera) hay cuarenta millas, al Peñón de Ifach (Yabal Kalb) hay ocho millas, a la ciudad de Alicante hay cuarenta y dos millas, de Alicante al Cabo de Santa Pola (Taraf al-Nazur) hay diez millas...»

Al-Idrīsī es una de las fuentes principales para el conocimiento del territorio alicantino en época islámica por la cantidad y la calidad de información que recoge en sus textos.

\section{AL-ZUHRĪ (s. XII)}

Al-Zuhrī, conocido también como el «Anónimo de Almería», posiblemente era originario de esta ciudad. De él apenas se tienen datos biográficos, a excepción de los contenidos en su propia obra y que permiten situarlo en el espacio y en el tiempo. Su obra «Kitāb al-Dja 'Rāfiyya» fue escrita hacia el año 1147 y se presenta en forma de comentario del mapamundi del califa abbasí al-Mamūn. Muchos de los datos contenidos en la obra fueron recogidos por el propio al-Zuhrī, ya fuera personalmente o de boca de algunos informadores. En base a sus experiencias personales, rectificó afirmaciones de algunos geógrafos anteriores.

Su obra constituye una fuente de datos no solo sobre la concepción que tenía un andaluz del siglo XII acerca de la geografía del mundo, sino también sobre la vida económica, social, política e incluso cultural de la Península Ibérica en su época. Al-Zuhrī murió entre los años 1154 y 1161.

Texto:

«En el litoral y a 16 parasangas de Játiva, está la ciudad de Denia, que es grande. Dicen que la fundaron los cartagineses que vivieron en esta tierra en tiempos de Moisés (;sobre él la paz!). Sus habitantes tienen los rostros amarillentos a causa de las algas que les arroja el mar a la orilla, formando grandes montículos cuyo olor sube hasta ellos y les arrebata la belleza de sus rostros y les produce delgadez y palidez. En Denia hay un gran castillo llamado Qasr al-Hubur, que no tiene parangón. La ciudad posee también muchos árboles; sus montes se caracterizan por los naranjos y los algarrobos excelentes, que van goteando su néctar. Luego, también en la costa y a poniente, siguen las ciudades de Alicante y Cartagena.»

\section{YĀQŪT (siglos XII-XIII)}

Abū Abd Allāh Yāqūt ibn Abd Allāh al-Hamāwi al-Bagdādī, es más conocido como Yāqūt (Jacinto, como significa su nombre en árabe). Pero su verdadero nombre no debió ser Yaqūt, pues en la época de este autor era costumbre de nominar a los esclavos como Yāqūt, Kāfūr, Lu’lu’, etc.

Yāqūt nació en territorio bizantino del Asia Menor, hacia el año 1179 y sus padres no eran árabes, sino quizás griego-bizantinos; por eso a veces aparece con el nombre de al-Rūmī. 
En su infancia fue capturado y sacado de su lugar natal y conducido después a Bagdad, donde fue vendido a un mercader originario de Hama (Siria). Le envió a la escuela, sin duda con la intención de sacar provecho de él en beneficio propio posteriormente, y le hizo llevar la contabilidad de sus transacciones comerciales.

Las distintas fuentes que suministran datos sobre Yāqūt resaltan su rendimiento, su estudio y una formidable capacidad de trabajo; Yāqūt debió ser un hombre de espíritu agudo, despierto y batallador por alcanzar su propia meta. A lo largo de su vida realizó numerosos viajes donde conoció numerosas ciudades.

En la ciudad de Marw en 1218 concibió la idea de confeccionar el «Mu 'yam albuldān» («Diccionario de los países»), que debió terminar el año 1224. Yāqūt murió en Alepo en agosto de 1229.

Texto:

\section{Aryūl (Orihuela)}

«Se denomina así una ciudad situada al este de al-Andalus, en el término agrícola (nahiya) de Tudmir. De ella es originario Abū Bakr Atiq b. Ahmad b. Abd al-Rahmān al-azdi al-andalusī al-Aryūlī, quien viajó hasta Alejandría, donde conoció al hafiz Abd Tāhir Ahmad b. Silfa. Después marchó hacia La Meca, donde permaneció algunos años perfeccionando sus conocimientos sobre la doctrina malikí. Regresó más tarde a al-Magrib, donde acabó sus días.»

\section{Uriyūla (Orihuela)}

«Es el nombre de una ciudad antigua de las dependencias de al-Andalus, perteneciente al distrito agrícola de Tudmir. Sus campos lindan con los de Murcia.

Es originario de ella Abū-l-Qāsim Jalaf b. Sulaymān b. Jalaf b. Muh b. Fathūn alUriyūlī, quien transmitió noticias tomadas de su padre, de Abū-l-Walid al-Baȳ̄ y de otros. Era jurista, literato y excelente poeta. Fue nombrado cadí en Játiva y Denia. Escribió un libro acerca de formularios notariales. Murió en el año 505 (1112).

Su hijo, Muhammad b. Jalaf b. Sulaymān b. Jalaf b. Fathūn al-Uriyūlī Abū Bakr, dio noticias referidas por su padre y otros más. Era un hombre ilustrado en la ciencia de la tradición y considerado como uno de los más entendidos en la misma, conocedor de los nombres de sus cultivadores. Escribió varios libros.»

La ciudad de Orihuela aparece mencionada dos veces y con grafías distintas en la obra de Yāqūt. Algunos de los personajes originarios de Orihuela mencionados por Yāqūt ya aparecieron en la obra de al-Rusātī (siglos XI-XII).

\section{Altāya (Altea)}

«Es el nombre de una alquería del término de Denia, perteneciente al distrito agrícola de la Sierra (iqlim al-Yabal), en al-Andalus. 
De ella es originario el gramático Abū Zayd Abd al-Rahmān b. Amir al-Ma afirī alAltaī, quien estudió la obra de Sibawayh con el gramático de Denia Abū Abd Allāh Muh b. Jalsa al-Kafîf (el ciego); aprendió las tradiciones del poeta con Abū-l-Qāsim Jalaf b. Fathūn al-Uriyūlī, y de otros.

Era destacado humanista y buen poeta. Entre sus discípulos figura su sobrino Abū Ya'far 'Abd Allāh b. 'Āmir al-Ma 'Āfirī al-Altāī, el cual fue discípulo del gramático Abu Bakr al-Labātī y de otros más. Fue también un buen poeta. Aprendió las «siete lecturas coránicas» de Abū 'Abd Allāh Muh b. Al-Hasan b. Sa'id al-Dānī. Fue muy apto para la rectación coránica, pero tenía más aptitud para la literatura y la poesía.»

$$
\text { Als (Elche) }
$$

«Es una ciudad de al-Andalus, de las dependencias de Tudmir. Es muy célebre por sus exquisitas pasas y sus excelentes palmeras que sólo se cultivan en esta región de alAndalus. Tiene también fama por sus excelentes alfombras que no tienen semejante en el mundo entero.»

\section{Bitrīr (Petrel)}

«Es el nombre de un castillo de las dependencias de Murcia, en al-Andalus.»

\section{Butrūs}

«Es el nombre de un balad dependiente de Denia, en al-Andalus.

De allí procede Abū Marwān 'Abd al-Mālik b. Muh. B. Umayya b. Sa'id b. Attāl al-Dānī al-Butrūsī. Fue discípulo de Ibn Sukkarra al-Saraqustī y de otros maestros de Córdoba. Fue nombrado cadí en Denia. Era uno de los más destacados eruditos, según noticias de al-Silafī.»

Butrūs podría corresponder al actual Tossal del Moro, de Benilloba, situado en la partida del Pla de Petrosa (GUICHARD, 1985).

\section{Bayrān (Bairén)}

«Es una alquería dependiente de Denia, en al-Andalus.

Es originario de ella Abū Hafs Umar b. Abd al-Razzāq al-Bayrān̄̄ al-Nafz̄̄. Fue al Oriente para realizar la peregrinación a La Meca y se encontró con al-Silafī. Le recitó algunos versos y le dijo que él había visto a Abū-l-Hasan Alī b. Abd al-Ganī al-Qayrawānī en Denia, que es una de las ciudades de al-Andalus, y en Tánger, que es una de las ciudades del norte de África. Murió en Tánger y aprendió mucho de Abū Hafs. Era un gran maestro, al que unía una gran amistad con al-Silafī.»

El castillo de Bairén se encuentra en el término actual de Gandía (Valencia), a unos kilómetros de la ciudad, en un cerro situado cerca de la actual carretera de Valencia (actual castillo de San Juan). 


\section{Dāniya (Denia)}

«Es una ciudad de al-Andalus dependiente de Valencia. Está situada a la orilla del mar, por el Este tiene un puerto maravilloso llamado al-Summān. Posee excelentes tierras de cultivo y alquerías. Abundan en ella los higos, las uvas y las almendras.

Era la residencia del rey Abū-l-Hasan Muyāhid al-Āmirī. Sus habitantes son los mejores lectores coránicos y el propio rey era su mecenas.

De ella es el más destacado de los maestros en la lectura coránica, Abū Amr b. Sa īid al Dānī, autor de obras acerca de los siete métodos de la lectura del Corán.

Alī 'Abd al-Gānī al-Husarī recitó los versos siguientes en memoria de sus hijos:

«Me resigno ante la voluntad de Dios que me arrebató en Denia mi única fortuna: dos trozos de mis entrañas.»

\section{Furqusa}

«Es un castillo dependiente de Denia, en al-Andalus. De allí proceden los vestidos de Furqusa (al-aksiya al-Furqusiyya).»

El castillo de Furqusa dependiente de Denia ha sido identificado con el importante yacimiento de El Castellar de Alcoy (AZUAR, 1989).

\section{Qāūn (Mongó)}

«Es el nombre de un monte en al-Andalus, cerca de Denia, muy alto, visible a una distancia de dos días.»

\section{Qusantāna (Cocentaina)}

«Es el nombre de un castillo maravilloso dependiente de Denia, en al-Andalus. Lleva la nisba con referencia a Cocentaina Abū-l-Walīd b. Jamis al-Qusantāni, uno de los visires de los Banū Muyāhid al-Amirī.»

\section{Qalyūs (Callosa de Segura)}

«Está situada a una distancia de seis millas de Orihuela, en al-Andalus, ¡Dios sabe si es verdad!».

\section{Munastīr}

«Al-Munastīr está al Este de al-Andalus entre Laqant (Alicante) y Cartagena.»

El término al-Munastīr es una voz híbrida, de monasterio y el artículo árabe. Al-Munastīr significa «el monasterio» dando lugar a topónimos como Almonáster o Almonacid. Así por ejemplo en Huelva tenemos la actual Almonáster La Real; y lo mismo sucede en la 
provincia de Alicante. Creemos como Azuar (AZUAR, 1987) que éste al-Munastîr situado por Yāqūt entre Alicante y Cartagena corresponde a la rábita califal de Guardamar del Segura (siglos IX-XI). Si bien ya en el siglo XII, cuando Yāqūt escribe su obra, éste sería ya un lugar abandonado quedaría en el recuerdo de las gentes como «al-Munastīr» (AZUAR et alii, 1989).

\section{AL-QAZWĪNĪ (s. XIII)}

Zaqariyā b. Muhammad b. Mahmūd al-Qazwīn̄in, nació en Qazwīn, Persia septentrional hacia el año 1203. Como típico representante del hombre de letras de su época, marchó a completar su formación en Damasco y otras ciudades orientales. Compartió su labor como geógrafo y cosmógrafo con la actividad de juez o cadí en las ciudades de Hilla y Wasit.

Su obra, el «Ātār al-bilād», es un estudio geográfico, un diccionario de países del mundo, en el que estos, las ciudades y lugares, se hallan distribuidos en un estricto orden alfabético dentro de cada uno de los siete climas establecidos en la clásica división tolemaica.

Al-Qazwīnī murió en 1283.

Texto:

\section{Elche (Als)}

«Esta ciudad andalusí está situada cerca de Tudmir. Entre los privilegios de esta localidad hay que mencionar su palmeral, sin igual en todo el país. Se dan en Elche unos higos secos que no se encuentran en ningún otro lugar de al-Andalus, que se exportan desde aquí al resto del territorio. En esta ciudad hay artesanos que elaboran magníficos tapices sin parangón en todo al-Andalus.»

\section{AL-MAGRIBĪ (s. XIII)}

Abū-l-Hasan Alí ibn Sa id al-Magribī nació en torno al año 1210 cerca de Granada y murió entre los años 1274 y 1286. Fue poeta, antólogo, historiador y geógrafo; fue autor último de una obra, el «Kitāb al-mugrib», comenzada por un antepasado suyo, más de un siglo antes, y continuada por los miembros de su familia hasta llegar a él.

Texto:

«Ciudad de Villena (Bilyana): Ciudad de muy hermosas vistas; posee aguas y huertos; está al norte de Murcia.

Ciudad de Elche (Alsh): Dice un autor: «No hay en al-Andalus buenos frutos si no es en Elche». Dice Ibn Sa'id: «pasé por esa ciudad, y lo que predominaba en sus tierras eran los saladares. Dicen que se parece a Medina (la ciudad) del Profeta, la paz sea con él.»

Ciudad de Orihuela (Aryula): Cuando viajé desde Murcia al mar, pasé por Orihuela, y me pareció que el lugar en que estaba situada era como un trozo del Paraíso Eterno, que hubieran arrancado y puesto allí: el río caudaloso; las chirriantes norias, como venas 
sangrantes; los pájaros, lanzando sus trinos; los árboles, abrazados unos a otros. Y tiene una fortaleza que es lo máximo en inexpugnabilidad.

Ciudad de Alicante (Laqant): Hay allí gran producción, especialmente de higos y de aceite, y su vino es digno de mención: es un vino muy apreciado y famoso por su fuerza. Tiene esta ciudad un puerto donde fondean las naves grandes; es éste el puerto de Murcia: la gente se hace a la mar desde aquí para ir a Ifriqiya. Su fortaleza es tan alta que parece que abrocha con botones el cielo: nunca vi en al-Andalus ciudadela más inexpugnable que ésta.»

\section{ĀD-DIMASHQI (s. XIII-XIV)}

Shams ad-dīn ād-Dimashqi, vivió en Bagdad. Fue autor del «Nujbat ad-Dahr...», obra desprovista de riguroso sentido crítico, pero que contiene gran cantidad de informaciones que no se encuentran en otras obras. Ād-Dimashqi murió en torno al año 1327.

Texto:

«Tiene esta ciudad (Murcia) un río que corre por su parte meridional y le llega de la parte de Segura (Shaqura), desembocando en el mar por al-Muddawwar.»

Destacamos en este texto una nueva mención a la enigmática Almodóvar, en la desembocadura del río Segura.

«Orihuela (Uryula): Se afirma que Orihuela es Tudmir; es éste el nombre de un rey suyo antiguo, al que los musulmanes arrebataron dicho territorio en la época de la conquista.»

Esta confusión de Orihuela con la capital de la cora aparece en otros autores árabes. Más que Orihuela, lo probable es que fuera Murcia la que un tiempo fue llamada Tudmir; recuérdese lo dicho por Yāqūt: «se le dio a Murcia el nombre de Tudmir (...), pero persistió la gente en llamarla con el nombre anterior de su emplazamiento.»

\section{AL-HIMYARĪ (s. XIV)}

Abū Abd Allāh Muhammad ibn Abd al-Mun’im al-Himyarī, más conocido como alHimyarī, es originario de Ceuta y vivió durante el siglo XIV. Recopiló alfabéticamente todas las noticias sobre la Península Ibérica; este compendio recibe el nombre de «Kitāb ar-rawd al-Mi'tar fī habar al-aktār.»

La versión definitiva de su obra se debe casi con toda seguridad a un descendiente suyo llamado Abū Abd Allāh Muhammad b. Muhammad al-Himyarī, muerto entre los años 1494 y 1495 .

Texto:

\section{Ūriyūla (Orihuela)}

«Fortaleza de al-Andalus, dependiente del territorio de Tudmir. Fue una de las siete localidades mediante la remisión de las cuales fue acordada la paz por Abd al-'Azīz b. 
Mūsā b. Nusair a Tudmir, hijo de Abdūs, cuando éste último fue vencido por este general y reducido por los musulmanes a sus últimos límites. Se firmó un tratado, que estipulaba la entrega de estas plazas y el pago de un impuesto por cabeza. La plaza de Orihuela era la capital de Teodomiro. Hablaremos con más detalle de este personaje a propósito de Cartagena.

Entre Orihuela y Elche hay una distancia de veintiocho millas. La ciudad de Orihuela, que es antigua y data de tiempos remotos, fue una capital de los agam y la sede de uno de sus reinos. Su nombre en latín significa «la que es de oro». Esta ciudad está provista de una ciudadela muy bien defendida, sobre la cima de una colina. Está rodeada de jardines y huertos, donde los frutos crecen en abundancia. La vida allí es fácil; posee tiendas y explotaciones agrícolas. Está a doce millas de Murcia y a cuarenta y cinco de Cartagena. Abū 'l-Walīd al-Bāgī desempeñó allí el cargo de cadí.»

\section{Als (Elche)}

«En al-Andalus. El distrito de Elche forma parte del círculo de Tudmir, y su cabeza de partido se encuentra a quince millas de Orihuela.

Elche es una ciudad situada en una llanura; está atravesada por un brazo del río vecino, que pasa bajo las murallas, abastece las termas (baños) y atraviesa tiendas y calles; su agua es salobre.

De Elche a Alicante hay veinticinco millas de distancia. Se cuenta, entre otras curiosidades, que sobre la orilla cercana a Elche, en el fondeadero llamado Santa Pola, hay piedras llamadas «las piedras del lobo»: si se toca con ellas un lobo o un león, estos animales pierden todo deseo ofensivo y abandonan su ferocidad natural.»

\section{Dāniya (Denia)}

«Ciudad del Levante de al-Andalus.

Situada a orillas del mar, está poblada y es de hermoso aspecto. Posee un arrabal muy poblado. Está rodeada de una sólida muralla que, en su lado Este, se prolonga hasta el mar: su construcción denota habilidad y competencia. Denia está provista igualmente por una ciudadela muy fuerte. La ciudad se encuentra en una región en que los cultivos se suceden sin interrupción, con numerosos jardines de higueras y viñedos. Su puerto está muy frecuentado por los navíos. De allí salía la flota musulmana para el corso; la mayor parte de los barcos de que estaba compuesta eran construidos en la misma Denia, ya que poseía un astillero naval. Al sur de la ciudad hay un pico circular, desde cuya cima se divisa, en alta mar, las montañas de Ibiza.

Era natural de Denia, Abū Amr ad-Dān̄i, especialista en lecturas coránicas, conocido bajo el nombre de Ibn as-Sairafī, y autor de obras sobre recensiones del Corán. En alAndalus fue discípulo de Muhammad b. Abd Allāh ibn Ab̄̄ Zamanīn; fue a Oriente y oyó a numerosos maestros. Murió en Denia en el año 444 (1053).» 


$$
S(a) g(a) s(\operatorname{Sax})
$$

«Ciudad de al-Andalus, cerca de Petrel. Es un pueblo importante y próspero. Está a poca distancia de Játiva.»

\section{Sanfīro}

«Castillo de al-Andalus, a cuatro jornadas de Murcia, al Este de esta última ciudad. Es famoso por su solidez.

Muhammad ibn Hūd se apoderó de él durante un periodo de paz, en el año 614 (12171218), con un ejército de 500 regulares. Lo tomó por sorpresa en las condiciones siguientes: Abu Sa 'îd, hijo del saih Abū Hafs al-Hintāti, había visitado, uno tras otro, los castillos de al-Andalus, durante la ronda de inspección que efectuó en la tregua convenida con el enemigo. Habiéndose fijado en esta plaza, cuya sólida construcción se destacaba contra el cielo, quedó admirado y dijo: «¿Cómo han podido arrebatar a los musulmanes semejante castillo?». Le respondieron: «Se apoderaron de él por sorpresa, en pleno periodo de paz. «A lo que replicó: «¿No habrá entre todos los soldados del ejército musulmán, ninguno capaz de devolverles el golpe?» Ibn Hūd oyó esto y se prometió a sí mismo ser ese hombre. Una vez preparada la estrategia que iba a emplear, trepó por la muralla del castillo por medio de una escala de cuerda, y ahogó al vigía encargado de la guardia nocturna. Sus hombres, uno tras otro, subieron tras él, y llegaron a reunirse todos dentro del castillo. Los cristianos que escaparon a la matanza que se desarrolló, huyeron y se refugiaron en el interior de un sólido torreón. Ibn Hūd dijo entonces: «Si estos fugitivos logran mantenerse hasta mañana en ese torreón, van a recibir refuerzos de todas partes ¡Así que mi opinión es que hay que prender fuego a la puerta! «Cuando los refugiados vieron subir el humo y aumentar el incendio, pidieron la paz, con la autorización de evacuar esos lugares. Les fue concedido, y los musulmanes tomaron posesión del castillo.

Durante la noche los cristianos habían hecho deslizarse a un hombre a lo largo del muro del torreón, encargándole que diera la alarma a sus compatriotas. Al día siguiente por la mañana, caballeros y soldados de infantería rodeaban el castillo, pero, ante la resistencia de los musulmanes, se retiraron, llenos de despecho por haber visto fracasar su tentativa.

Una serie de cartas relativas a la toma de este castillo se dirigieron hacia Marrakech. El visir Ibn Gāmi'dijo a Ibn al-Fahhār: «Lo hemos tomado en tiempo de paz, ya que en tiempo de paz se nos tomó». Este asunto fue la base de la fama que adquirió Ibn Hūd entre los habitantes de Levante en al-Andalus, que decían: «¡Por él debíamos haber recuperado Sanfīro y gracias a él lo hemos recuperado!».

Este castillo de Sanfīro sólo es mencionado por al-Himyarī. Este episodio ofrece un doble interés histórico. En primer lugar porque no sabemos cómo las fuerzas cristianas pudieron apoderarse de aquella fortaleza en territorio tan avanzado de la frontera; y en segundo lugar, esta hazaña, le valió a Ibn Hud la fama como valeroso guerrero, que después aprovecharía para que sus partidarios le siguieran en el momento de su alzamiento en 1228 contra el opresor almohade.

Hoy por hoy no conocemos la localización de la fortaleza de Sanfīro, aunque Huici Miranda lo identificó con San Pedro del Pinatar, a menos de 50 km. de Murcia, a orillas del 
Mar Menor. Por nuestra parte creemos que tal localización es incorrecta por dos razones. La primera es la distancia que da al-Himyarī entre Murcia y Sanfīro, que es de cuatro jornadas hacia el Este. San Pedro estaría, como mucho, a dos jornadas de Murcia. Además en San Pedro del Pinatar no hay restos de una gran fortaleza musulmana. Todo lo cual nos lleva a proponer que la fortaleza de Sanfīro estaría situada en alguno de los numerosos restos de fortificaciones musulmanas de las montañas del norte de la provincia de Alicante.

\section{Lakant (Alicante)}

«En el país de al-Andalus, a 70 millas de Denia, siguiendo la costa.

Es una ciudad pequeña, pero poblada; está provista de un bazar y una mezquita, con púlpito. Es un centro de exportación de esparto hacia todos los países marítimos. Su territorio produce frutos y legumbres en abundancia, sobre todo higos y uva. La ciudad está dotada de una ciudadela muy fuerte, situada en la cima de un monte al que se llega con gran esfuerzo. A pesar de su exigüidad, Alicante es un centro de construcciones navales: allí se fabrican barcos de gran tonelaje y brulotes. De Alicante a Elche hay una jornada de camino por tierra.»

$$
\text { 'Afs (Aspe) }
$$

«En al-Andalus, cerca de Murcia.

Los cristianos infligieron allí una derrota a los habitantes de Murcia, en el mes de Rayab de aquel año. Las pérdidas de los murcianos, tanto en muertos como en prisioneros, se elevaron a unos cuatro mil hombres. Esta derrota fue provocada por una salida de los murcianos contra los cristianos, que habían hecho una incursión en la región. Por la misma época los Rum (cristianos) habían atacado de forma semejante a los sevillanos y los habían derrotado en la llanura de Tejada. En aquella ocasión los murcianos habían tachado a los sevillanos de débiles, de falta de medios y de inexpertos en la guerra; pero poco tiempo después fueron probados cruelmente por Allāh con esta derrota. El jefe del ejército de Murcia era aquel día Abū 'Alī ibn Asarkī.

El autor de al-Mutamis ha dicho: Lo de 'Afs fue semejante a lo de Tejada, de lo que ya se habló en el año 621 (1224); lo uno se desarrolló en el Occidente de al-Andalus, lo otro en el Levante del mismo país. Los adoradores de la cruz habían avanzado hasta 'Afs, localidad dependiente del gobierno de Murcia. Las tropas de esta ciudad, acompañadas por el populacho, salieron para atacar al enemigo; muchos de los murcianos resultaron muertos, otros muchos fueron hechos prisioneros.»

El topónimo 'Afs es identificado por Rafael Azuar (AZUAR, 1983) con el Castillo del Río (Aspe) y que aparece denominado en los documentos cristianos del siglo XIII como «Azpe el Viejo» para diferenciarlo de «Azpe el Nuevo», que ya correspondería a la actual Aspe. Este 'Afs o Azpe el Viejo se despoblaría hacia los años 1264 y 1268, pues después de estas fechas ya no vuelve a mencionarse Azpe el Viejo, sólo la ciudad actual de Aspe. Su último señor fue Abū Zayd, y con su muerte comenzaría el despoblamiento de 'Afs. 


\section{Karbalyān (Crevillente)}

«Localidad de al-Andalus, a veinte millas de Orihuela. Posee numerosos olivares y se beneficia de un abundante regadío.»

\section{AL-QALQASANDI (s. XIV-XV)}

Al-Qalqasandi (1355-1418) era probablemente de origen egipcio. Su obra se titula «Subh al-A'sa fī kitābāt al-insā». En el volumen V de esta obra, al-Qalqasandi dedica un capítulo a España, el cual constituye una descripción geográfica de la Península y un breve relato histórico de los estados cristianos y musulmanes españoles que alcanza el reinado del nasrí granadino Muhammad VII (1391-1407).

Al-Qalqasandi, conocía España sólo por referencias y su información no es nada original. Sin embargo su obra reviste el interés de ofrecernos en forma sintética una visión de conjunto sobre España a principios del siglo XV.

Texto:

\section{Denia}

«La ortografía del nombre de esta ciudad es Daniya.

Situada en el Levante andaluz, en el principio del quinto clima, con posición geográfica de $19^{\circ} 10^{\prime}$ de longitud y $37^{\circ}$ 6' de latitud, según Ibn Sa id, está al Oeste de Valencia, junto al mar.

Es una ciudad de gran valor y de mucho bienestar. Tiene algunas fortalezas.

En la actualidad ha llegado a formar parte del reino de Barcelona juntamente con Valencia, como se expresará en el capítulo de los reinos cristianos de al-Andalus, si Dios quiere.»

\section{DIKR BILĀD AL-ANDALUS (s. XV)}

La última fuente que recogemos en este trabajo es un texto anónimo conocido como «Dikr bilād al-Andalus» (Descripción del país de al-Andalus). Su autor o compilador anónimo era de origen magrebí (Marruecos). El Dikr debió ser redactado en la primera mitad del siglo XV. No es una obra original, ni siquiera una compilación de fuentes seleccionadas, sino simplemente una obra hecha a base de retales de desigual valor.

Texto:

«La ciudad de Denia

-Dios la restituya al islam por su gracia-

Es una ciudad de tipo medio situada a orillas del mar, terrestre y marítima, bien fortificada, rica en todo tipo de bienes, frutos y huertos; su puerto es muy importante. 
Frente a ella, en el mar, se encuentran las islas de Ibiza, Menorca y Mallorca. Tanto Denia como estas islas son consideradas parte de al-Andalus porque su lengua es idéntica, su dialecto es igual y su soberano, el mismo. Esto era en tiempos pasados.»

\section{BIBLIOGRAFÍA}

ARIÉ, R., España musulmana (siglos VIII-XV), Barcelona, 1984.

ASIN PALACIOS, M., Contribución a la toponimia árabe de España, Madrid, 1944.

AZUAR RUIZ, R., «Panorama de la arqueología medieval de los valles Alto y Medio del Vinalopó, Alicante», Lucentum, II, 1983, pp. 347-383.

— «El posible al-Monastir de las Dunas de Guardamar del Segura (Alicante)», Les illes orientales d'al-Andalus, V Jornades d'Estudis Històrics Locals (Palma de Mallorca, 1985), Palma de Mallorca, 1987, pp. 265-311.

- Denia islámica. Arqueología y poblamiento, Alicante, 1989.

- «Una rábita hispanomusulmana del siglo X (Guardamar del Segura, Alicante, España)», Archéologie Islamique, 1, 1990, pp. 109-122.

AZUAR RUIZ, R. et alii, La rábita, califal de Guardamar del Segura (Alicante): cerámica, fauna, malacofauna y epigrafía. Memorias de excavaciones arqueológicas, Museo Provincial de Alicante, Alicante, 1989.

AZUAR RUIZ, R. y GUTIÉRREZ LLORET, S., «Formación y transformación de un espacio agrícola islámico en el área Sur del País Valenciano: el Bajo Segura (siglos IX-XIII)», Castrum 5. Archéologie des espaces agraires méditerranéens au Moyen Ầge. Archéologie de l'habitat fortifié (Murcia, 1992), pp. 201-211.

AL-BAKRI, Kitab al-masalik wa-l-ma malik; VIDAL BELTRÁN, E., Geografía de España (trad. cas. de la parte de al-Andalus), Zaragoza, 1982.

BARCELÓ TORRES, C., «Almodóvar, una población de la Cora de Tudmir sepultada en las dunas de Guardamar del Segura», Saitabi, XXXV, 1985, pp. 59-71.

BRAMON, D., «El Levante peninsular andalusí en la geografía de al-Zuhri», Al-Qantara, VI, 1985, pp. 517-524.

CARMONA GONZÁLEZ, A., «Noticias geográficas árabes referentes al Bilad Tudmir», Murgetana, 72, 1987, pp. 115-122.

- «Recorrido por la geografía histórica de la Murcia islámica», Guía Islámica de la Región de Murcia, Murcia, 1990, pp. 13-30.

CODERA, F., «Inscripción árabe de Guardamar», Boletín de la Real Academia de la Historia, XXXI, 1897, pp. 31-33.

CHEJNE, A., Historia de España musulmana, Madrid, 1993.

Dikr bilad al-Andalus, Una descripción anónima de al-Andalus, MOLINA, L. (ed. y trd.), 2 vols., Madrid, 1983.

EPALZA FERRER, M. de, «Al topónimo de Guardamar». Revista del Instituto de Estudios Alicantinos, 32, 1980, pp. 204-210.

- «Estudio del texto de al-Idrisi sobre Alicante», Sharq al-Andalus, 2, 1985, pp. 215233.

- «Costas alicantinas y costas magrebíes: el espacio marítimo musulmán según los textos árabes», Sharq al-Andalus, 3, 1986, pp. 25-31. 
- «Costas alicantinas y costas magrebíes: el espacio marítimo musulmán según los textos árabes (2)», Sharq al-Andalus, 4, 1987, pp. 45-48.

GARCÍA ANTÓN, J., «Sobre los orígenes de Tudmir», Antigüedad y Cristianismo, II, Murcia, 1985, pp. 369-383.

— «Las ciudades de Alicante durante el islam», Historia de la Provincia de Alicante, III, Alicante, 1985.

GARCÍA MENÁRGUEZ, A.,«Sobre la localización del topónimo Almodóvar en la desembocadura del Segura». Sharq al-Andalus, 6, 1989, pp. 149-157.

GASPAR REMIRO, M., Historia de Murcia musulmana, Zaragoza, 1905.

GUICHARD, P., «Murcia musulmana (siglos IX-XIII), Historia de la Región Murciana, III, Murcia, 1980, pp. 133-185.

- «El islam alicantino», Historia de la Provincia de Alicante, III, Alicante, 1985.

GUTIÉRREZ LLORET, S., «La geografía del Bajo Segura según al-Udri (s. XI): una propuesta de identificación de la alquería de Tall al-Jattab», Alquibla, Revista de investigación del Bajo Segura, 1, 1995, pp. 65-93.

AL-HIMYARI, Kitab al-Zawd al-mi'tar fi jabas al aqtar; MAESTRO GONZALEZ, P., Kitab al-Zawd al-mi'tar, Valencia, 1963.

AL-IDRISI, Nuzhat al-Musaq, trad. cas. UBIETO, Idrisi, Geografía de España, Valencia, 1974.

LEVI-PROVENÇAL, E., «La Description de l'Espagne d'Ahmed al-Razi», Al-Andalus vol. XVIII, 1953, pp. 51-108.

LOZANO, J., Bastitania y Contestania del Reino de Murcia, Murcia 1794. Reimpresión de la Academia Alfonso X el Sabio, Murcia, 1980.

MOLINA LÓPEZ, E., «La cora de Tudmir según al-'Udri (s. XI). Aportaciones al estudio geográfico-descriptivo del SE. peninsular». Cuadernos de Historia del Islam, 4, (serie monográfica $\mathrm{n}^{\circ}$ 3) 1972.

- «Noticias geográficas y biográficas sobre Tudmir en el Iqtibas al-anwar de al-Rusati». Homenaje al Profesor Torres Fontes, II, Murcia, 1987, pp. 1085-1089.

AL-QALQASANDI, Subh al-a'Sa fi Kitabat al-insa, trad. cas. SECO DE LUCENA, Valencia, 1975.

AL-RAZI, CATALÁN, D. y DE ANDRÉS, Ma J., Crónica del Moro Rasis, versión del Ajbar muluk al-Andalus de Ahmad ibn Muhammad ibn Musa al-Razi, 889- 935; romanzada para el rey don Dionís de Portugal hacia 1300 por Mahomad, alarife, y Gil Pérez, clérigo de Perianes Porçel, 1975.

ROLDÁN CASTRO, F., «El oriente de al-Andalus en Atar bilad de al-Qazwini» Sharq al-Andalus, 9, pp. 29-46.

TORRES FONTES, J., Repartimiento de Orihuela, Murcia, 1988.

VALLVÉ BERMEJO, J., «La división territorial de la España musulmana (II): La Cora de Tudmir (Murcia)», Al-Andalus, XXXVII, 1972, pp. 145-198.

AL-YA'QUBI, Kitab al-buldan, trad. francesa de WIET, G., Les Pays, El Cairo, 1937.

YAQUT, Mu'yam al-buldan, trad. cas. parte relativa a al-Andalus, GAMAL 'ABD ALKARIM, «La España musulmana en la obra de Yaqut (siglos XII-XIII). Repertorio enciclopédico de ciudades, castillos y lugares de al-Andalus. Extraído del Mu'yam al-buldan, Cuadernos de Historia del Islam, 6, Granada, 1974. 